\title{
The Effects of Hydrogen Peroxide and Deposition Temperature on the electrodeposited Zinc Oxide Film
}

\author{
Jee-Ray Wang ${ }^{1}$, Miao-Ju Chuang ${ }^{1}$, Yuan-Gee Lee ${ }^{1, *}$, Der-Wei Chen ${ }^{2}$, Kung-Hsu Hou ${ }^{2, *}$ \\ ${ }^{1}$ Department of Automation Engineering and Institute of Mechatronoptic Systems, Changhua, Taiwan. \\ ${ }^{2}$ Department of Power Vehicle and Systems Engineering, Chung Cheng Institute of Technology, \\ National Defense University, Taoyuan, Taiwan. \\ *E-mail: yglee@cc.ctu.edu.tw, khou@ndu.edu.tw, khoucloud@gmail.com
}

doi: $10.20964 / 2016.10 .57$

Received: 22 May 2016 / Accepted: 19 August 2016 / Published: 6 September 2016

\begin{abstract}
Zinc oxide ( $\mathrm{ZnO})$ film was successfully electrodeposited on a substrate of indium-tin oxide (ITO) by reduction of zinc chloride. It was found that both the content of hydrogen peroxide and the electropostion temperature dominated the microstructure variation and its optical properties. The morphology of $\mathrm{ZnO}$ film revealed different growth mechanism, i.e. film with large flake-like crystal without $\mathrm{H}_{2} \mathrm{O}_{2}$ in contrast to the fine surface with $\mathrm{H}_{2} \mathrm{O}_{2}$ included. During electrodeposition, organometallic compound, $\mathrm{Zn}_{5}(\mathrm{OH})_{8} \cdot \mathrm{H}_{2} \mathrm{O}$, co-precipitated on the electrode which was depressed by hydrogen peroxide $\left(\mathrm{H}_{2} \mathrm{O}_{2}\right)$ and burn-out in an annealing process. Besides, $\mathrm{H}_{2} \mathrm{O}_{2}$ could result of crystal defects in $\mathrm{ZnO}$ to produce new doped-energy level, $\mathrm{E}_{\mathrm{d}}$, and thus reduce the photon energy as a redshift. On the other hand, the under substrate could affect the transmittance to induce blue-shift caused by the lattice distortion at the interlayer, $\mathrm{ZnO} / \mathrm{ITO}$.
\end{abstract}

Keywords: zinc chloride, hydrogen peroxide, microstructure variation, doped-energy level

\section{$\underline{\text { FULL TEXT }}$}

(C) 2016 The Authors. Published by ESG (www.electrochemsci.org). This article is an open access article distributed under the terms and conditions of the Creative Commons Attribution license (http://creativecommons.org/licenses/by/4.0/). 